\title{
CCL2 is Upregulated by Decreased miR- 122 Expression in Iron-Overload-Induced Hepatic Inflammation
}

\author{
Yuxiao Tang ${ }^{\mathrm{a}}$ Wentao Jia ${ }^{\mathrm{b}}$ Xiaowen Niu Lusha Wu $^{\mathrm{a}}$ Hui Shen ${ }^{\mathrm{a}}$ Lina Wang ${ }^{\mathrm{b}}$ \\ Ruirui $\mathrm{Qj}^{\mathrm{a}}$ Changquan Ling ${ }^{\mathrm{b}} \quad \mathrm{Min} \mathrm{Li}^{\mathrm{a}}$ \\ aMilitary Hygiene Department, Faculty of Naval Medicine, Second Military Medical University, Shanghai, \\ bDepartment of Traditional Chinese Medicine, Changhai Hospital, Second Military Medical University, \\ Shanghai, China
}

\section{Key Words}

Iron overload • Hepatic inflammation • Chemokine (C-C motif) ligand $2(C C L 2) \cdot \operatorname{miR}-122$

\begin{abstract}
Background/Aims: Iron overload (IO) is accompanied by hepatic inflammation. The chemokine (C-C motif) ligand 2 (CCL2) mediates inflammation, and its overexpression is associated with IO. However, whether IO results in CCL2 overexpression in the liver and the underlying mechanisms are unclear. Methods: We subjected mice to IO by administering intraperitoneal injections of dextran-iron or by feeding mice a 3\% dextran-iron diet to observe the effects of IO on miR-122/CCL2 expression through real-time qPCR and Western blot analysis. We also used indicators, including the expression of the inflammatory cytokine, the inflammation score based on H\&E staining and the serum content of ALT and AST to evaluate the effects of IO on hepatic inflammation. Meanwhile, we observed the effects of vitamin E on IO-induced hepatic inflammation. In cells, we used $100 \mu \mathrm{M} \mathrm{FeSO}_{4}$ or $30 \mu \mathrm{M}$ Holo-Tf to produce IO and observed the roles of miR-122 in regulating CCL2 expression by using miR-122 mimics or inhibitors to overexpress or inhibit miR-122. Then, we used a dual-luciferase reporter assay to prove that miR-122 regulates CCL2 expression through direct binding to its complementary sequence in the CCL2 mRNA 3'UTR. Results: IO induces the downregulation of miR-122 and the upregulation of CCL2, as well as inflammatory responses both in vitro and in vivo. Although IO-induced oxidative stress is eliminated by the antioxidant vitamin E, IO-induced hepatic inflammation still exists, which probably can be explained by the fact that vitamin $\mathrm{E}$ has no effects on the miR-122/CCL2 pathway. In in vitro experiments, the overexpression and inhibition of miR-122 significantly reduced and increased CCL2 expression, respectively. The dual-luciferase reporter assay indicates that miR-122 binds CCL2 mRNA 3'UTR. Conclusion:
\end{abstract}

Y. Tang, W. Jia and X. Niu contributed equally to this work.

Min Li

and Changquan Ling 


\section{Cellular Physiology Cell Physiol Biochem 2017;44:870-883 \begin{tabular}{l|l|l} 
and BOI: 10.1159/000485355 & $\begin{array}{l}\text { C } 2017 \text { The Author(s). Published by S. Karger AG, Basel } \\
\text { www.karger.com/cpb }\end{array}$
\end{tabular}}

Tang et al.: Iron Overload Induces Hepatic Inflammation Through CCL2

We propose the roles of miR-122/CCL2 in IO-induced hepatic inflammation. Our studies should provide a new clue for developing clinical strategies for patients with IO.

\section{Introduction}

Iron is an essential cofactor for several fundamental cellular processes, such as cellular respiration, DNA synthesis and oxygen transport. The liver stores a large amount of iron and tightly regulates iron homeostasis by producing hepcidin, an iron regulatory hormone. Impaired iron metabolism has been found to be associated with hepatic inflammation in many liver diseases, particularly with non-alcoholic fatty liver disease [1] and acute or chronic liver failure [2]. In addition, hepatic iron overload is associated with increased infiltration of neutrophils, macrophages, and CD8-positive lymphocytes and increased expression of the pro-inflammatory cytokines, interleukin-6 (IL-6), interleukin-1beta (IL-1 $\beta$ ), and tumour necrosis factor-alpha (TNF $\alpha$ ) [3]. However, the underlying molecular factors behind these inflammatory responses have not been further pursued.

Chemokine (C-C motif) ligand 2 (CCL2), also named monocyte chemoattractant protein-1 (MCP-1), is a small cytokine that triggers hepatic inflammation. As a consequence of tissue injury, liver cells, such as Kupffer cells, stellate cells, and hepatocytes, secrete CCL2 to provoke the massive accumulation of monocytes in the injured liver [4]. Thereby, CCL2 signalling links hepatic and systemic inflammation related to metabolic disorders [5]. Its overexpression has been found in a number of liver diseases, including alcoholic [6] and nonalcoholic fatty liver disease [7], hepatic fibrosis [8], hepatic necrosis [9] and hepatocellular carcinoma [10]. However, whether IO results in CCL2 overexpression in the liver is currently unclear.

miR-122 is a microRNA that is abundantly and selectively expressed in the liver. In a study investigating liver-specific and germline knockout of miR-122, CCL2 was reported to be significantly increased ( $>3$-fold) [11]. In contrast, another group reported controversial results using an independent mouse model with germline knockout of miR-122 [12]. At the same time, Castoldi, et al. reported that miR-122 is involved in maintaining systemic iron homeostasis [13]. It has been observed that miR-122 is decreased in patients with iron overload disorders as well as in a related genetic mouse model. In addition, depletion of miR-122 in wild-type mice led to increased mRNA expression of activators of hepcidin transcription, which in turn caused systemic iron deficiency [13]. However, it is still unclear whether IO downregulates miR-122 expression in the liver.

Taken together, the current study aimed to fully investigate the role of the miR-122/CCL2 pathway in IO-induced hepatic inflammatory responses. Specifically, we document that, both in vitro and in vivo, IO results in significant reduction of miR-122 expression. Meanwhile, the CCL2 expression and hepatic inflammatory responses are significantly enhanced by IO.

\section{Materials and Methods}

\section{Animal Studies}

All animal studies were performed at the Second Military Medical University, Shanghai, China, with the approval of the Second Military Medical University Institutional Animal Care and Use Committees. All animals received human care. C57BL/ 6 mice weighing $13 \pm 2 \mathrm{~g}$ (mean $\pm \mathrm{SD}$ ) at 4 weeks of age were purchased from the Slac Laboratory Animal, Int., Shanghai, China. For the Vit.E intervention experiment, 24 mice were randomly divided into 4 groups $(n=6)$ : control, iron overload (IO), iron overload plus corn oil (IO+corn oil) and iron overload plus vitamin E (IO+ Vit.E). We intraperitoneally injected PBS into the control group mice and dextran-iron into the mice in the other three groups at a concentration of $200 \mathrm{mg} / \mathrm{kg}$ twice a week. Vit.E was dissolved in corn oil, and intragastric administration at $100 \mathrm{mg} / \mathrm{kg}$ was carried out simultaneously with the injection. For the i.p. injection iron overload experiment, 36 mice were randomly divided into 3 groups according to the time of injection: 1 week, 2 weeks and 4 weeks. Each group had 2 subgroups $(n=6)$ : 


\section{Cellular Physiology Cell Physiol Biochem 2017;44:870-883 \begin{tabular}{ll|l} 
and Biochemistry & $\begin{array}{l}\text { DOI: 10.1159/000485355 } \\
\text { Publisned online: November 24, } 2017\end{array}$ & $\begin{array}{l}\text { @ 2017 The Author(s). Published by S. Karger AG, Basel } \\
\text { www.karger.com/cpb }\end{array}$ \\
\hline
\end{tabular}}

Tang et al.: Iron Overload Induces Hepatic Inflammation Through CCL2

mice that received i.p. injection of PBS were designated control mice, and mice that received i.p. injection of dextran-iron at $200 \mathrm{mg} / \mathrm{kg}$ were designated iron-overload (IO) mice. The injections were performed twice per week. For the iron-rich diet experiment, 12 mice were divided into 2 groups: control and 3\% dextraniron diet. Mice in the control group were fed a cereal-based diet containing adequate iron, and mice in the 3\% dextran-iron diet group were fed 3\% dextran-iron for one month. For the vehicle experiment, i.p. injection with an equivalent amount of dextran was used as a negative control. As a substitution vehicle of dextran iron, we i.p. injected sucrose-iron containing an equivalent amount of iron as a positive control. Mice also received i.p. injection twice a week for 4 weeks at a concentration of $200 \mathrm{mg} / \mathrm{kg}$. Vitamin E, dextran, dextran iron and sucrose iron were purchased from Sigma-Aldrich, USA. Corn oil was produced from the China Oil \& Foodstuffs Corporation (Shanghai, China).

\section{Detection of hepatic indicators of oxidative stress damage}

For detection of the ROS content, first liver tissue was homogenized and centrifuged to obtain the supernatant. Then, we incubated the supernatant with the ROS detection probe DCF $(5 \mu \mathrm{M})$ at $37^{\circ} \mathrm{C}$ in the dark for $1 \mathrm{~h}$. We used a microplate reader to record the fluorescence intensity of the samples. For detection of the SOD activity and the MDA and GSH contents, detection kits were purchased from Jianchen Biotech, Nanjing, China, and all operations strictly followed the manual instructions. For detection of 8-OHdG, we used immunofluorescence to detect the 8-OHdG content in the liver. Anti-8-OHdG was purchased from Abcam, UK.

\section{Cell cultures and chemicals}

Huh7 cells were purchased from Zhongqiaoxinzhou Biotech Inc. (Shanghai, China) and treated as described previously $[14,15]$. Cells were grown in high-glucose DMEM medium with $10 \%$ fetal bovine serum, $100 \mathrm{IU} / \mathrm{ml}$ penicillin, and $50 \mu \mathrm{g} / \mathrm{ml}$ streptomycin sulphate. All medium, supplements, and Dulbecco's phosphate-buffered saline for cell culture were purchased from HyClone, USA. $\mathrm{FeSO}_{4}$ was purchased from Sigma-Aldrich, USA. Apo-transferrin (apo-Tf) and holo-transferrin (holo-Tf) were purchased from Merck Millipore, Germany. Both the transferrin preparations were absent of LPS, as indicated by the Limulus amebocyte lysate assays, for which the rapid Endotoxin detection kit Pyrosate was purchased from ACC, Inc., U.S.A. The miR-122 inhibitor and miR-122 mimics were purchased from RiboBio, Guangzhou, China.

\section{Cell viability and intracellular iron detection}

Cell viability was determined by the CCK8 assay (Beyotime Biotechnology, Nantong, China). For detection of the intracellular iron, we used a fluorescence quenching method with the Phen Green ${ }^{\mathrm{TM}} \mathrm{FL}$ reagent (Thermo Fisher, US), following the manufacturer's instructions. Quenched fluorescence meant that iron ions were permeated into the cells.

\section{Transfection in vitro}

Cell transfection was performed by lipofectamine RNAiMAX (for miRNA inhibitors and mimics) or by lipofectamine 3000 (for plasmids), according to the manufacturer's instructions [16]. We transfected cells with miR-122 mimics at a concentration of $50 \mu \mathrm{M}$ and miR-122 inhibitors at a concentration of $100 \mu \mathrm{M}$. Cells were harvested for the downstream experiments, such as qRT-PCR and Western blot analysis, at $48 \mathrm{~h}$ post-transfection.

\section{Dual-Luciferase Reporter Assay}

Plasmids of GP-miRGLO (Genepharma, Shanghai, China) containing either the wild-type or mutated CCL2 mRNA 3'UTR were co-transfected with miR-122 mimics or negative control in Huh7 cells. Forty-eight hours after transfection, the cells were lysed for luciferase activity with a Dual-Luciferase® Reporter Assay System (Promega, Mannheim, Germany), and firefly luciferase activity was normalized to Renilla luciferase activity.

\section{Western Blot Analysis}

Western blot assays were performed as previously described [17], with modification. Briefly, the Total Protein Extraction Kit (KeyGEN BioTECH, Nanjing, China)was used to extract total protein from the mice tissues and cultured cells. Following normalization for protein concentration by using BCA kits 
(Thermo Fischer, US), the samples were separated using 12\% SDS-PAGE electrophoresis, electrotransferred to a nitrocellulose membrane and probed with relevant primary antibodies at $4{ }^{\circ} \mathrm{C}$ overnight: CCL2 antibodies (1:400), p65 antibody (1:1000), I $\kappa$ B $\alpha$ antibody (1:1000), p-ІкB $\alpha$ antibody (1:1000), TNF $\alpha$ (1:1000), IL-6 $(1: 1000)$ and $\beta$-actin antibody (1:3000). All antibodies were purchased from Cell Signaling Technology, USA; Protech, USA; or Santa Cruz, USA. Greyscale image data using GeneSnap from the SynGene software package were normalized to the $\beta$-actin abundance.

Quantitative Real-time PCR Analysis

Total RNA from the liver tissues or cells was extracted

Table 1. Primers for RT-qPCR

\begin{tabular}{|c|c|}
\hline Primer & Sequence \\
\hline hsa- $\beta$-actin & $\begin{array}{l}\text { Forward }\left(5^{\prime}-3^{\prime}\right) \text { : ACACCTTCTACAATGAGCTG } \\
\text { Reverse }\left(5^{\prime}-3^{\prime}\right) \text { : CATGATGGAGTTGAAGGTAG }\end{array}$ \\
\hline hsa-CCL2 & $\begin{array}{l}\text { Forward }\left(5^{\prime}-3^{\prime}\right) \text { : CAGTTGCTGAGAAGCCTGAC } \\
\text { Reverse }\left(5^{\prime}-3^{\prime}\right) \text { : AAACCGAGAACGAGATGTGG }\end{array}$ \\
\hline hsa-p65 & $\begin{array}{l}\text { Forward }\left(5^{\prime}-3^{\prime}\right) \text { : CCACCCGGCTTCAGAATGG } \\
\text { Reverse }\left(5^{\prime}-3^{\prime}\right) \text { : GGTATGGGCCATCTGCTGTT }\end{array}$ \\
\hline hsa-TNF $\alpha$ & $\begin{array}{l}\text { Forward }\left(5^{\prime}-3^{\prime}\right) \text { : ATTGCCCTGTGAGGAGGAC } \\
\text { Reverse }\left(5^{\prime}-3^{\prime}\right) \text { : TGAGCCAGAAGAGGTTGAGG }\end{array}$ \\
\hline hsa-IL-6 & $\begin{array}{l}\text { Forward }\left(5^{\prime}-3^{\prime}\right): \text { TACATCCTCGACGGCATCTC } \\
\text { Reverse }\left(5^{\prime}-3^{\prime}\right): \text { TTTCAGCCATCTTTGGAAGG }\end{array}$ \\
\hline hsa-pri-miR-122 & $\begin{array}{l}\text { Forward }\left(5^{\prime}-3^{\prime}\right): \text { GACAAGGTTCCCCTATTATCAGTG } \\
\text { Reverse }\left(5^{\prime}-3^{\prime}\right): \text { CAAAGCAAACGATGCCAAGAC }\end{array}$ \\
\hline hsa-pre-miR-122 & $\begin{array}{l}\text { Forward }\left(5^{\prime}-3^{\prime}\right): \text { CCTTAGCAGAGCTGTGGAGTG } \\
\text { Reverse }\left(5^{\prime}-3^{\prime}\right) \text { : GCCTAGCAGTAGCTATTTAGTGTGA }\end{array}$ \\
\hline mmu-18s & $\begin{array}{l}\text { Forward }\left(5^{\prime}-3^{\prime}\right): \text { GTAACCCGTTGAACCCCATT } \\
\text { Reverse }\left(5^{\prime}-3^{\prime}\right): \text { CCATCCAATCGGTAGTAGCG }\end{array}$ \\
\hline $\mathrm{mmu}-\mathrm{CCL} 2$ & $\begin{array}{l}\text { Forward }\left(5^{\prime}-3^{\prime}\right) \text { : TCTGTGCTGACCCCAAGAAGG } \\
\text { Reverse }\left(5^{\prime}-3^{\prime}\right) \text { : TGGTTGTGGAAAAGGTAGTGGAT }\end{array}$ \\
\hline $\mathrm{mmu}-\mathrm{p} 65$ & $\begin{array}{l}\text { Forward }\left(5^{\prime}-3^{\prime}\right) \text { : GACCTGGAGCAAGCCATTAG } \\
\text { Reverse }\left(5^{\prime}-3^{\prime}\right) \text { : CACTGTCACCTGGAAGCAGA }\end{array}$ \\
\hline $\mathrm{mmu}-\mathrm{TNF} \alpha$ & $\begin{array}{l}\text { Forward }\left(5^{\prime}-3^{\prime}\right) \text { : GCAGGTTCTGTCCCTTTCAC } \\
\text { Reverse }\left(5^{\prime}-3^{\prime}\right) \text { : TGCCACAAGCAGGAATGAG }\end{array}$ \\
\hline mmu -IL-6 & $\begin{array}{l}\text { Forward }\left(5^{\prime}-3^{\prime}\right) \text { : CGGAGAGGAGACTTCACAGA } \\
\text { Reverse }\left(5^{\prime}-3^{\prime}\right) \text { : ATTTCCACGATTTCCCAGAG }\end{array}$ \\
\hline $\mathrm{mmu}-\mathrm{IL}-1 \beta$ & $\begin{array}{l}\text { Forward }\left(5^{\prime}-3^{\prime}\right): \text { CCTCACAAGCAGAGCACAAG } \\
\text { Reverse }\left(5^{\prime}-3^{\prime}\right) \text { : CCAGCCCATACTTTAGGAAGAC }\end{array}$ \\
\hline mmu-pri-mir-122 & $\begin{array}{l}\text { Forward }\left(5^{\prime}-3^{\prime}\right): \text { CCAAACACCATTGTCACACTCCAG } \\
\text { Reverse }\left(5^{\prime}-3^{\prime}\right): \text { CTAGCTGGAGTGTGACAATGGTGTTTGGAGC }\end{array}$ \\
\hline
\end{tabular}
using TRIzol from Thermo Fisher, USA [18], and purified using the RNeasy Mini Kit from Qiagen, USA [19]. One microgram of total RNA was reversed-transcribed into cDNA using the RT reagent kit (Takara, Japan) with oligo-dT primers for mRNA or special RT stem-loop primers for microRNA. Mixed cDNA templates, primers, and SYBR green (Toyobo, Japan) reagents were subjected to the Step One Plus real-time system from Thermo Fisher, USA. All primers are listed in Table 1. The results were normalized to the $\beta$-actin (for mRNA) or U6 (for microRNA) abundance.

\section{Iron Status Parameters}

The liver iron level was quantitated using an atomic absorption spectrophotometer (Z-8100, Hitachi, Tokyo, Japan) and normalized to the dry tissue weight for each sample. Serum iron concentrations and TIBC in non-haemolysed serum samples were determined by KX-21 automated haematology analyser (Sysmex Co., Japan). The transferring saturation (TS) was calculated as the plasmatic iron/TIBC.

Table 2. Iron indicators in i.p. injection of dextran-iron mice. All data were determined as the mean $\pm \mathrm{SD}, *$ $\mathrm{P}<0.05,{ }^{* *} \mathrm{P}<0.01,{ }^{* * *} \mathrm{P}<0.001$ vs. Control

\begin{tabular}{lccc}
\hline & & Control & IO \\
\hline \multirow{2}{*}{ Liver iron $(\mu \mathrm{g} / \mathrm{g})$} & $1 \mathrm{~W}$ & $80.8 \pm 14.2$ & $1476 \pm 336^{* * *}$ \\
& $2 \mathrm{~W}$ & $80.2 \pm 17.1$ & $1583 \pm 399^{* * *}$ \\
Serum iron $(\mu \mathrm{Wmol} / \mathrm{L})$ & $4 \mathrm{~W}$ & $78.7 \pm 33.0$ & $4801 \pm 536^{* * *}$ \\
& $1 \mathrm{~W}$ & $22.5 \pm 4.9$ & $45.0 \pm 17.6^{*}$ \\
& $2 \mathrm{~W}$ & $16.5 \pm 5.3$ & $43.8 \pm 5.3^{* * *}$ \\
TIBC $(\mu \mathrm{mol} / \mathrm{L})$ & $4 \mathrm{~W}$ & $18.3 \pm 4.7$ & $47.1 \pm 6.5^{* * *}$ \\
& $1 \mathrm{~W}$ & $49.7 \pm 0.8$ & $59.2 \pm 9.4^{*}$ \\
TS $(\%)$ & $2 \mathrm{~W}$ & $51.0 \pm 6.7$ & $64.6 \pm 2.5^{* *}$ \\
& $4 \mathrm{~W}$ & $57.3 \pm 3.3$ & $91.1 \pm 1.8^{* * *}$ \\
& $1 \mathrm{~W}$ & $31.0 \pm 2.4$ & $63.1 \pm 10.2^{* * *}$ \\
& $2 \mathrm{~W}$ & $29.0 \pm 9.9$ & $61.6 \pm 5.2^{* * *}$ \\
\hline
\end{tabular}




\section{Liver Tissue Inflammation Score}

The scoring was quantified by pathologists according to standards of lok.Schener (1985) based on H\&E slides. A semi-quantitative scale was used: score 0-none; score 1-rare/mild; score 2-common/moderate; and score 3-frequent/severe.

\section{Statistics}

The t-test was used for two-group comparisons, and one-way ANOVA was used for multigroup comparison, if the data obeyed the normal distribution. If the data did not obey the normal distribution, the Mann-Whitney test was used for two-group comparisons, and the Kruskal-Wallis test was used for multigroup comparisons.

\section{Results}

IO affects miR-122/CCL2 pathway and triggers inflammatory responses in vivo, which is independent of route of administration and vehicle

Mice were fed a cereal-based diet that contained adequate iron. A subgroup of mice was intraperitoneally injected with dextran-iron and another group was injected with PBS. The liver iron content and serum iron content, as well as other serum iron indicators, such as serum total iron-binding capacity and serum transferrin saturation, were significantly enhanced over time after IO (Table 2). Prussian-blue-stained liver sections showed normal tissue

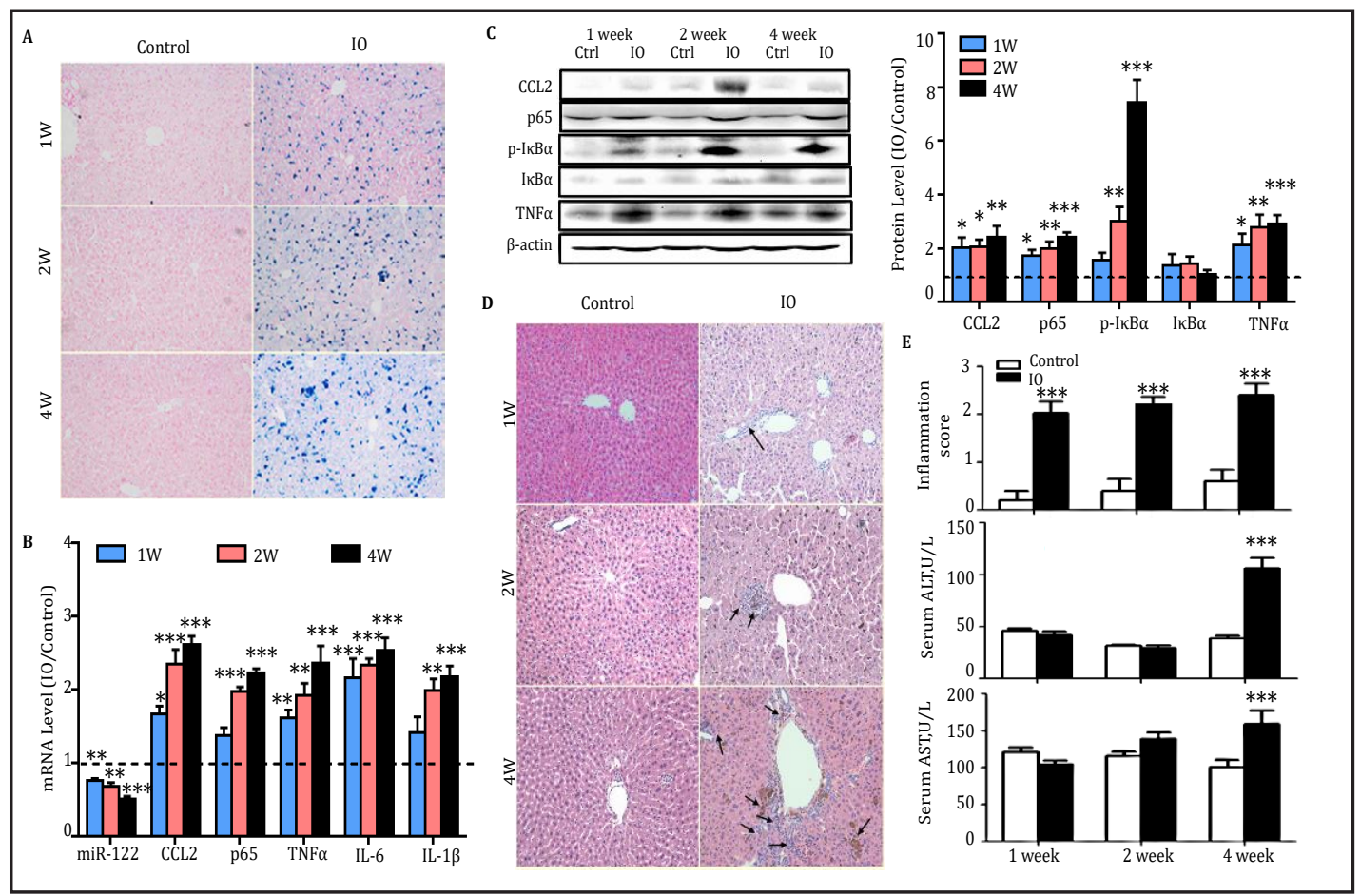

Fig. 1. Effects of iron overload on miR-122/CCL2 pathway and hepatic inflammation in vivo. Mice ( $N=6$ / group) were subjected to i.p. injection with PBS (Control) or $200 \mathrm{mg} / \mathrm{kg}$ of dextran iron (IO) at a frequency of twice per week. Mice were sacrificed, and liver sections were harvested at various time-points. (A) Prussian blue staining showed heavy iron accumulation in the liver. (B) The mRNA levels and (C) the protein levels of miR-122, CCL2 and various inflammatory factors were determined by qRT-PCR and Western blot assays. (D) H\&E staining showed increased immune cell infiltration (black arrow) in the liver after IO-treatment. (E) The inflammation score in the liver and serum ALT and ASL levels were determined. Data are normalized by the control group and represented as the mean \pm SEM. ${ }^{*} \mathrm{p}<0.05 ;{ }^{* *} \mathrm{p}<0.01{ }^{* * *} \mathrm{p}<0.001$ vs. Control. 
architecture with little stainable cells in the control group (Fig. 1A). In contrast, heavy iron a c cumulation was observed not only in the hepatic in te rcellular space but also inside the hepatocytes 4 weeks after iron administration

(Fig. 1A). These confirmed that mice became overloaded with iron. More importantly, IO led to a time-dependent decrease of miR-122 and a time-dependent increase of the inflammatory genes CCL2, NF- $\kappa \beta / p 65$, TNF $\alpha$, interleukin-6 (IL-6) and interleukin-1beta (IL-1 $\beta$ ) (Fig. 1B).

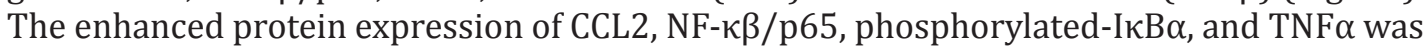
further confirmed by Western blot assays (Fig. 1C). In addition, H\&E staining revealed that the hepatic IO is associated with increased infiltration of neutrophils and macrophages (Fig. 1D). Both the hepatic inflammation scores and the serum activities of AST and ALT (Fig. 1E) were significantly increased upon iron administration over time.

To extend our findings to a different animal model of iron administration, a group of mice were fed a 3\% dextron-iron containing diet for 1 month and were compared to age-matched

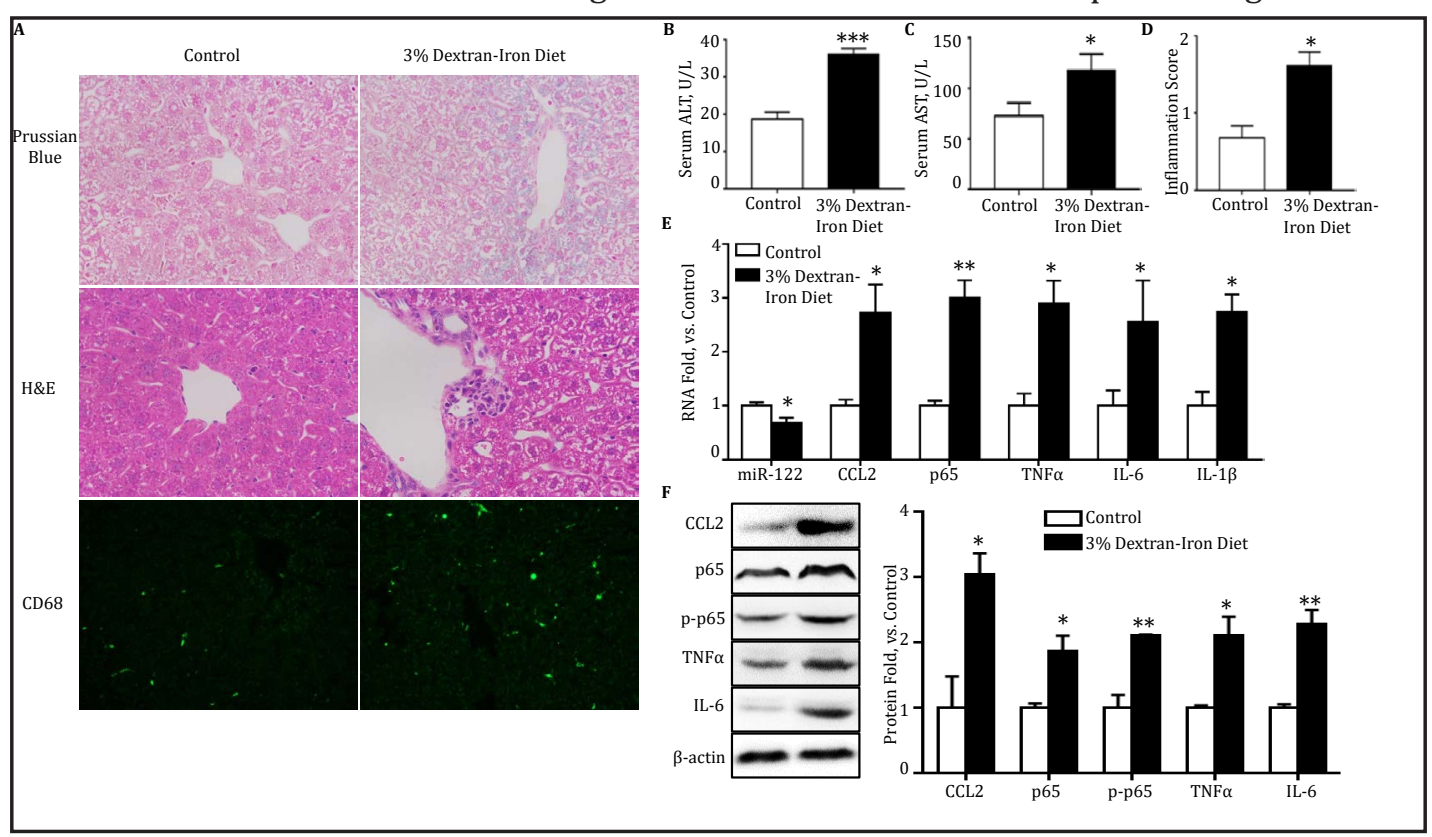

Fig. 2. Effects of a 3\% dextran-iron diet on miR-122/CCL2 pathway and hepatic inflammation in vivo. Mice $(N=6)$ received an iron-rich diet for 1 month to construct the iron overload model and mice $(N=6)$ with a normal diet were used as controls. (A) Prussian blue staining showed iron accumulation in liver. H\&E staining and immunofluorescence of CD68 showed infiltration of Kupffer cell. The serum content of ALT (B), AST (C) and the inflammation score of the H\&E stain (D) showed liver damage and inflammation. (E) Gene expression of miR-122, CCL2 and the inflammatory factors p65, TNF $\alpha$, IL-6 and IL-1 $\beta$. (F) Protein expression and greyscale comparison of CCL2, p65, TNF $\alpha$, IL- 6 and IL-1 $\beta$. Data are normalized by the control group and represented as the mean \pm SEM. ${ }^{*} \mathrm{p}<0.05 ;{ }^{* *} \mathrm{p}<0.01 ;^{* * *} \mathrm{p}<0.001$ vs. Control. 


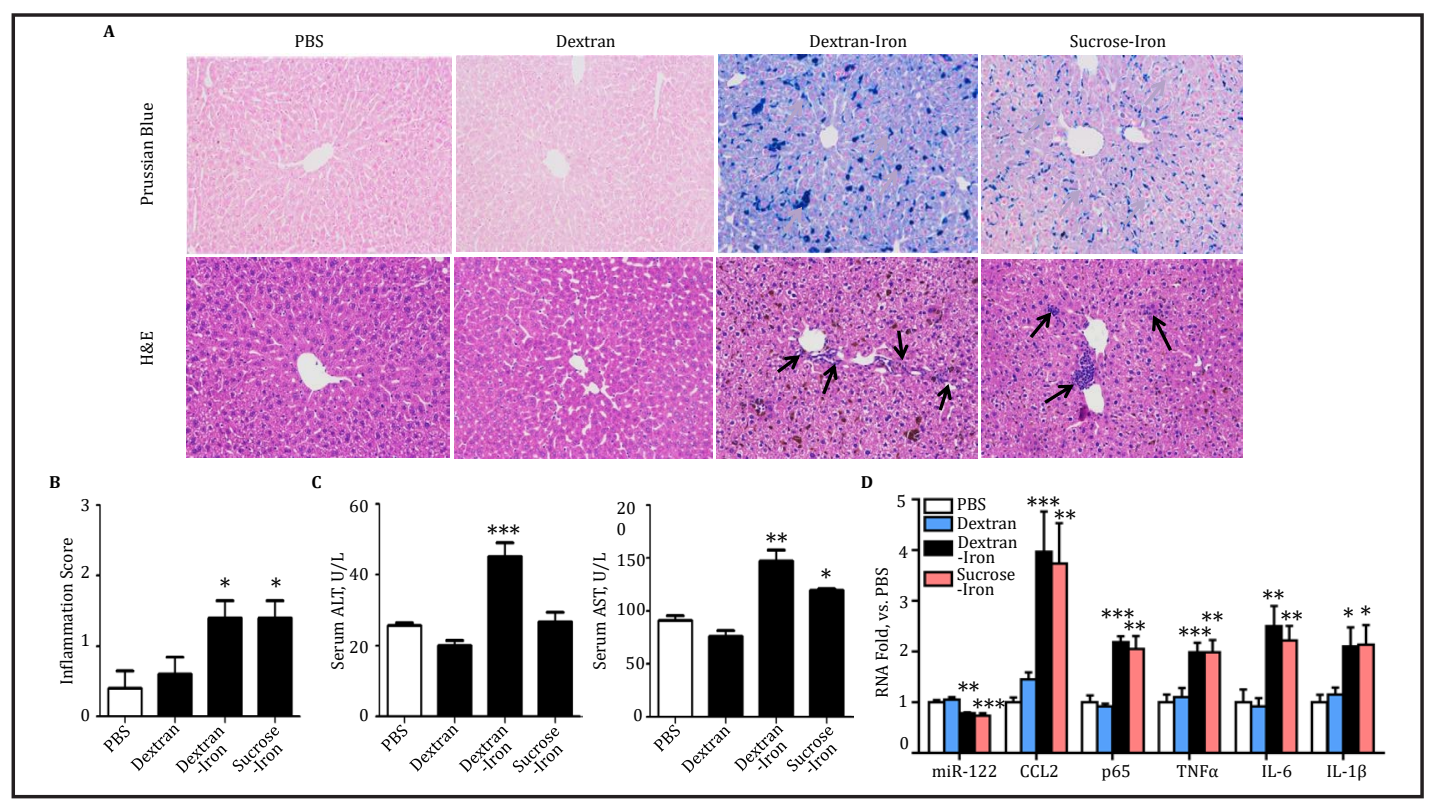

Fig. 3. IO-induced hepatic inflammation is independent of vehicle. C57BL/6 mice ( $\mathrm{N}=6 /$ group) were subjected to i.p. injection with $200 \mathrm{mg} / \mathrm{kg}$ of dextran, dextran iron or sucrose iron at a frequency of twice a week. Mice were sacrificed and liver tissues were harvested at week 4. (A) Prussian blue staining showed heavy iron accumulation. H\&E staining showed increased immune cell infiltration (black arrow) in the liver. (B) The inflammation score of the liver sections and (C) serum ALT and ASL levels were determined. (D) The mRNA levels of miR122, CCL2 and various inflammatory factors were determined by qRT-PCR. Data are normalized by the PBS group and represented as the mean \pm SEM. ${ }^{*} \mathrm{p}<0.05 ;{ }^{* *} \mathrm{p}<0.01$ vs. Dextran.

animals kept on standard chow. The liver iron content, serum iron content and other serum iron indicators were significantly enhanced (Table 3 ), as well as the iron accumulation in the liver, which was shown by Prussian-blue staining (Fig. 2A). Meanwhile, immune cell infiltration (Fig. 2A), serum transaminases (Fig. 2B, 2C), the hepatic inflammation score (Fig. 2D), and the serum content of TNF $\alpha$ and IL-6 (Table 3) were all determined to be significantly increased in iron-fed mice. More meaningfully, those mice displayed significantly elevated mRNA and protein levels of multiple inflammatory genes in the liver tissues (Fig. 2E and 2F), while expression of miR-122 was decreased.

Since there is a concern that the vehicle dextran may function as a potential immune modulator, we injected mice with PBS; dextran; dextran-iron; or sucrose-iron, another clinically used form of iron that can be absorbed by the body [20]. Clearly, heavy iron accumulation and infiltration of inflammatory cells can be found only in mouse livers that were injected with iron, but not vehicle controls (Fig. 3A). Similarly, both hepatic inflammation scores (Fig. 3B) and serum activities of AST and ALT (Fig. 3C) were elevated in the mice with IO. Most importantly, only IO treatment, regardless of the vehicle, significantly reduced the expression of miR-122 and increased expressions of inflammatory genes (Fig. 3D).

IO-induced hepatic inflammation cannot be eliminated by antioxidant Vit.E, which may be because Vit.E intervention has no effects on miR-122/CCL2 pathway

Considering that oxidative stress is a well-known mechanism of IO-induced hepatic inflammation, we planned to use the antioxidant Vit.E as an intervention and observe the effects of Vit.E as an anti-inflammatory reagent. For the design of experiment, we established 4 groups: Control, IO, IO+corn oil and IO+Vit.E. Prussian blue staining (Fig. 4A) and quantification of the liver iron content, serum iron content and other serum iron indicators (Table 4) showed that the 3 groups with injection of dextran-iron had significant accumulations of iron in the liver. Meanwhile, IO-induced oxidative stress seems to be eliminated by Vit.E according to 
the ROS, GSH, MDA and SOD results (Fig. 4C) and immunofluorescence of 8-hydroxydeoxyguanosine (8-OHdG), a marker of DNA damage induced by oxidative stress (Fig. 4A). However, hepatic inflammation, as shown by H\&E staining (Fig. 4A), ALT/AST serum content and the inflammation score (Fig. 4B) were not reversed by administration of Vit.E. In addition, gene expression (Fig. 4D) and protein expression (Fig. 4E) of the inflammatory factors NF- $\kappa \beta$ / p65, TNF $\alpha$ and IL- 6 exhibited the same change. A more meaningful result was that the mir$122 /$ CCL2 pathway was not changed by Vit.E intervention, which may be the reason why Vit.E intervention cannot alleviate IO-induced hepatic inflammation.

Taken together, these in vivo results suggest that hepatic inflammation induced by IO is not merely attributed to oxidative stress damages. Alterations of the miR-122/CCL2 pathway under IO seem to be involved in hepatic inflammation as well.

\section{IO regulates the expression of miR-122/CCL2 and results in significant inflammatory} responses in vitro

First, we evaluated the cytotoxicity of $\mathrm{FeSO}_{4}$ on a human hepatocyte cell line, Huh7. As shown in Fig. 5A, at 24 hours post-exposure, concentrations higher than $100 \mu \mathrm{M}$ of $\mathrm{FeSO}_{4}$ have significant effects on cell viability. Since the method of fluorescence signal quenching revealed that $100 \mu \mathrm{M}$ of $\mathrm{FeSO}_{4}$ treatment led to dramatic increases of intracellular iron content (Fig. 5B), in future experiments, this concentration was used to perform in vitro

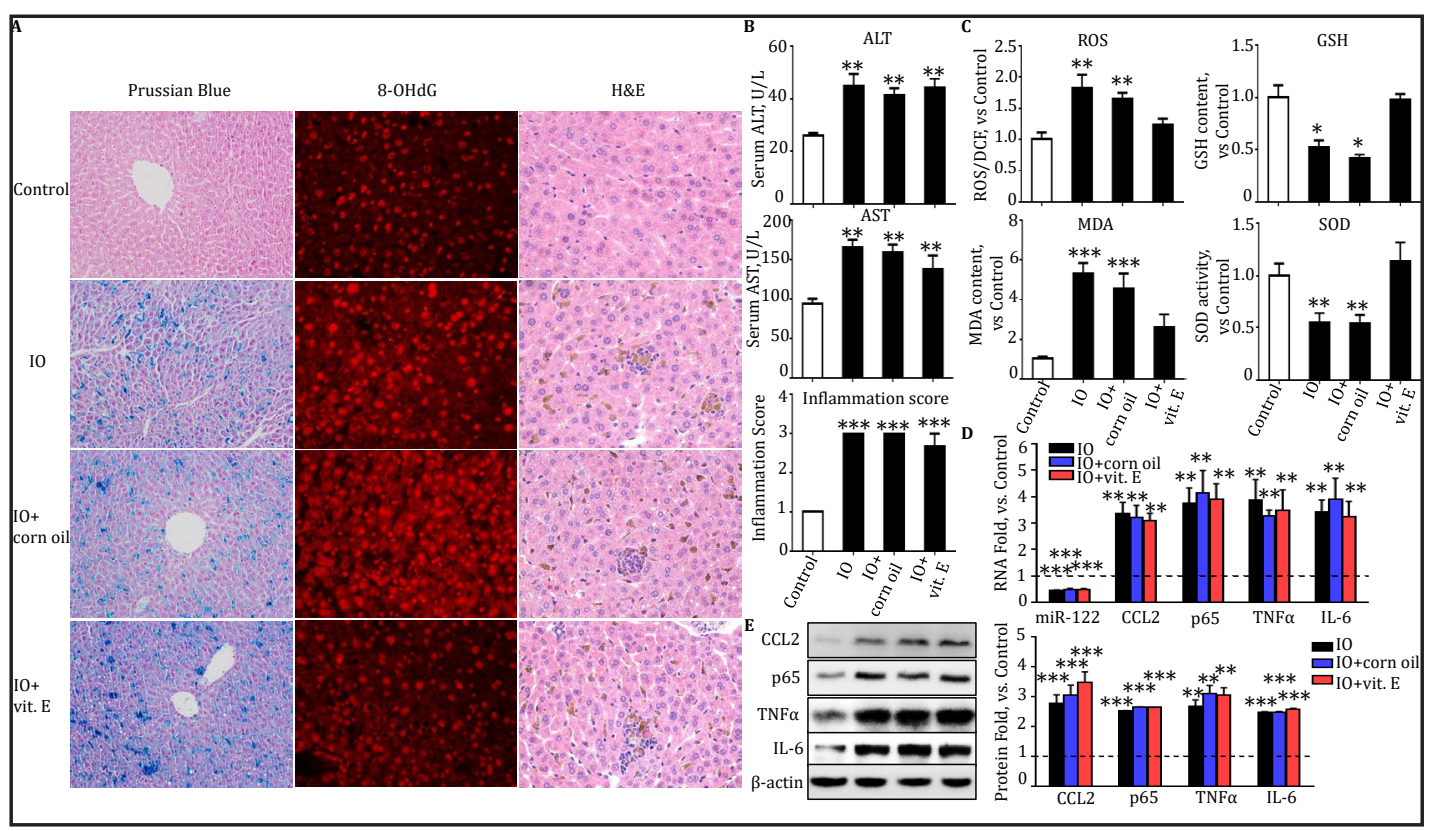

Fig. 4. Hepatic inflammation was induced by iron overload under the exist of antioxidant Vitamin E. Twentyfour mice were randomly divided into 4 groups to receive i.p injection of dextran-iron and intragastric administration of Vit.E for 4 weeks. (A) Prussian blue staining, immunofluorescence of 8-OHdG and H\&E staining of mice liver slides in the 4 groups. (B) Serum content of ALT/AST and the inflammation score. (C) Indicators of oxidative stress in mice liver, including ROS, GSH, MDA and SOD. (D) Gene expression of miR-122, CCL2, p65, TNF $\alpha$ and IL-6. (E) Protein expression and greyscale comparison of CCL2, p65, TNF $\alpha$ and IL-6. Data are normalized by the control group and represented as the mean \pm SEM. ${ }^{*} \mathrm{p}<0.05 ;{ }^{* *} \mathrm{p}<0.01$; $* * * \mathrm{p}<0.001$ vs. Control. 


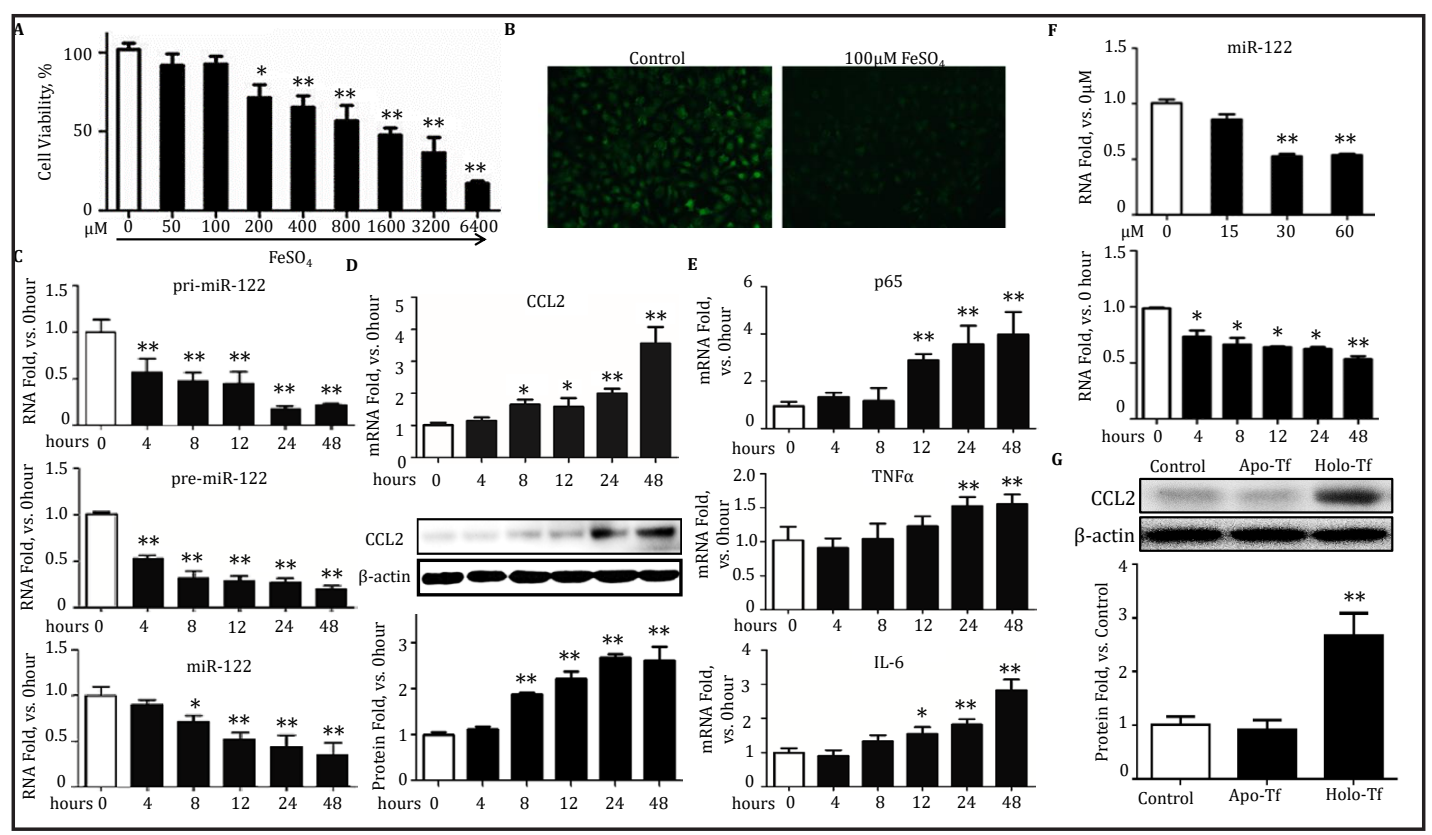

Fig. 5. The in vitro effects of IO on the expression of miR-122/CCL2 and inflammatory response. (A) Huh7 cells were treated with various concentrations of $\mathrm{FeSO}_{4}$ for 24 hours. Cell viability was determined using the CCK8 assay. (B) Phen Green-FL fluorescence signal quenching showed significant iron accumulation under the indicated concentration. ( $\mathrm{C}$ to E) Huh7 cells were treated with $\mathrm{FeSO}_{4}$ at $100 \mu \mathrm{M}$ for the indicated time. The expressions of (C) miR-122 in either the pre-, pri- or mature form, and (D) CCL2 at both the mRNA and protein levels was determined. (E) The mRNA levels of p65, TNF $\alpha$ and IL-6 were determined. (F) Huh7 cells were treated with Holo-Tf at various concentrations for $24 \mathrm{~h}$ or at $30 \mu \mathrm{M}$ for various time-points. The expressions of miR-122 were determined. (G) Huh7 cells were treated with Holo-Tf at $30 \mu \mathrm{M}$ for 24 hours. Cells treated with Apo-Tf were used as negative controls. The expression of CCL2 was determined. Data are normalized by the control group and represented as the mean \pm SEM. ${ }^{*} \mathrm{p}<0.05 ;{ }^{* *} \mathrm{p}<0.01 ;{ }^{* * *} \mathrm{p}<0.001$ vs. $0 \mathrm{~h}$ or $0 \mu \mathrm{M}$.

experiments. Huh7 cells were then treated with $\mathrm{FeSO}_{4}$ for various periods. Both the mRNA and protein expression of various genes were determined. The results indicated that $\mathrm{FeSO}_{4}$ treatment significantly reduced not only the expressions of the mature form but also those of the pri- and pre-form of miR-122 in a time-dependent manner (Fig. 5C). Finally, it was also evident that $\mathrm{FeSO}_{4}$ treatment resulted in significantly enhanced CCL2 expression at both the mRNA and protein levels (Fig. 5D).

Next, we investigated whether iron-overload could induce hepatic inflammatory

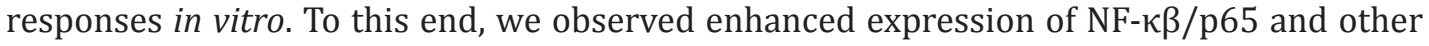
pro-inflammatory cytokines, including TNF $\alpha$ and IL-6 (Fig. 5E), upon $\mathrm{FeSO}_{4}$ treatment. Interestingly, the time-dependent assays demonstrated that the reduction of miR-122 occurred as early as 4 hours post-iron overload, followed by an increase in CCL2 that occurred an additional 4 hours later. Lastly, the enhanced expression of NF- $\kappa \beta / p 65$ and other pro-inflammatory cytokines was observed at a much later time points, 12 hours and 24 hours post-treatment, respectively. These results suggested that iron overload may first lead to the alteration of miR-122/CCL2 expression, which in turn results in the activation of the NF- $\kappa \beta$ signalling pathway and eventually the enhanced expression of the target genes, such as TNF $\alpha$ and IL-6.

Extracellular iron enters cells in the form of either iron ions or holo-Tf through the cellular membrane protein, TfR1. Thus, we also tested the ability of holo-Tf on the miR122/CCL2 pathway. As shown in Fig. 5F, the treatment of holo-Tf significantly reduced the 


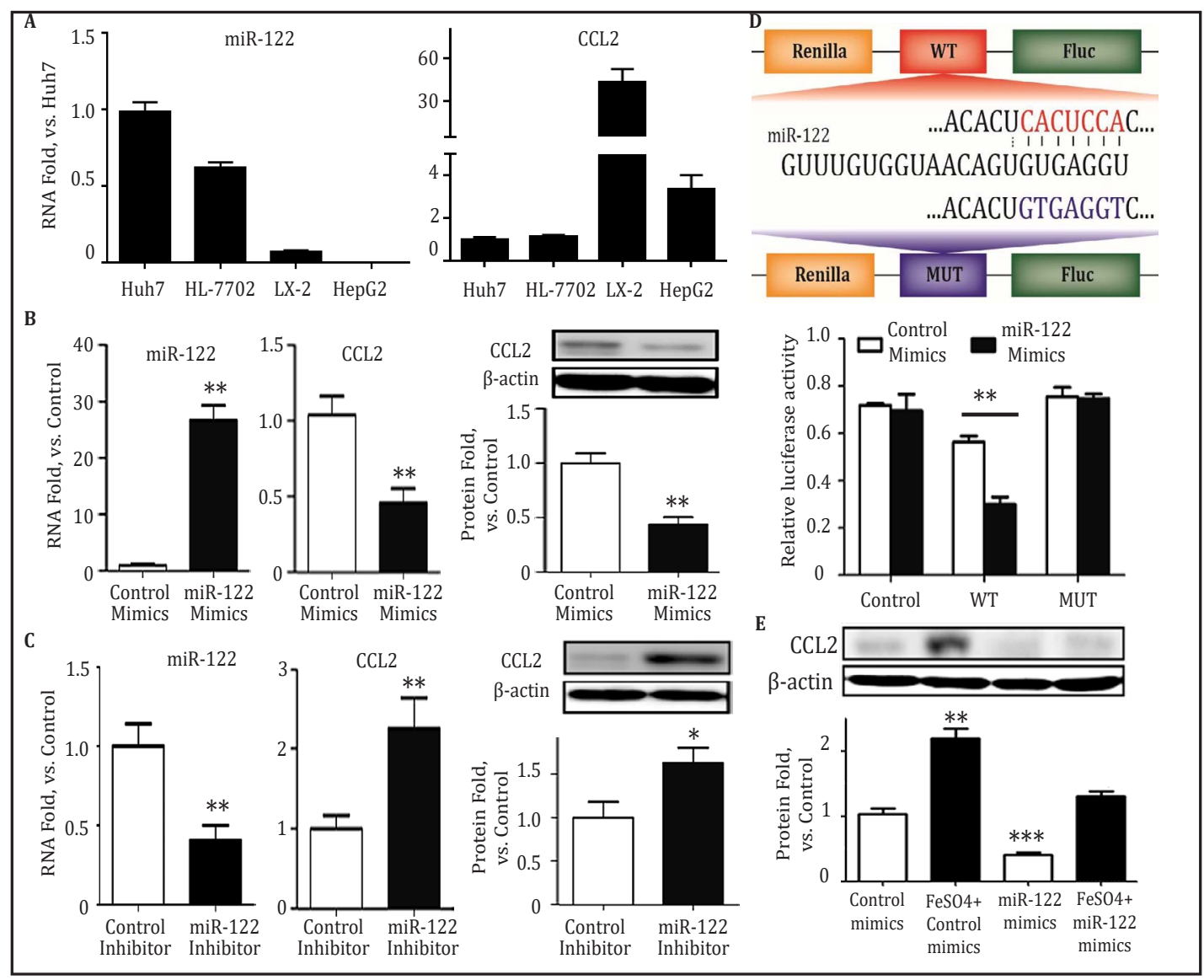

Fig. 6. The expression of inflammatory chemokine CCL2 is controlled by miR-122. (A) The expression of miR-122 and CCL2 at the mRNA level was determined in various hepatic cell lines. (B and C) Huh7 cells were either transfected with (B) miR-122 mimics or (C) miR-122 inhibitors. Control mimics or inhibitors were used to mock-transfect the cells. The expression of miR-122 and CCL2 mRNA at both the mRNA and protein levels was determined at $48 \mathrm{~h}$ post-transfection. (D) The schematic sequences of the wild-type (WT) 3'UTR of CCL2 mRNA that contains a potential miR-122 binding site and that of a mutant (MUT) 3'UTR are shown. Both WT and MUT sequences were cloned into GP-miRGLO plasmids. Both plasmids were transfected into Huh7 cells together with miR-122 mimics or control mimics. The relative luciferase activity of FLuc to Renilla was determined at $48 \mathrm{~h}$ post-transfection. (E) Huh7 cells were treated with $\mathrm{FeSO}_{4}$ at 100 $\mu \mathrm{M}$ and transfected with either negative control mimics or miR-122 mimics. The expression level of CCL2 protein was determined. Data are normalized by (A) the Huh7 cells or (B, C and E) the control group and represented as the mean \pm SEM. ${ }^{*} \mathrm{p}<0.05 ;{ }^{* *} \mathrm{p}<0.01$ vs. control.

miR-122 expression in both a time- and concentration-dependent manner. In addition, the CCL2 expression was increased by holo-Tf treatment (Fig. 5G). On the contrary, the negative control, Apo-Tf, had no effect on CCL2 expression. Taken together, our results indicated that iron overload affects the miR-122/CCL2 pathway to induce the hepatic inflammatory response.

\section{miR-122 controls CCL2 expression in vitro}

We first investigated the endogenous expression of both miR-122 and CCL2 in various hepatic cell lines. As shown in Fig. 6A, a negative correlation between the abundance of miR122 and CCL2 mRNA was observed, suggesting that miR-122 may negatively regulate the expression of CCL2. Next, we transfected Huh7 cells with either miR-122 mimics or inhibitors, as described in the Methods section. The results indicated that the overexpression of miR- 
122 reduced CCL2 expression at both the mRNA and the protein levels (Fig. 6B), whilst on the contrary, downregulation of miR-122 had the opposite effect (Fig. 6C). Furthermore, using the TargetScan online prediction software, we identified a potential miR-122 binding sequence at the 3'-UTR of CCL2 mRNA (Fig. 6D). Then, this region was subcloned into a GPmiRGLO plasmid carrying a firefly luciferase transgene and a Renilla luciferase transgene as an internal reference. The results of the transfection assays indicated that the WT 3'-UTR of CCL2 mRNA significantly reduced the relative luciferase activity in Huh7 cells. Moreover, coadministration of miR-122 mimics further reduction of the relative luciferase activity. On the contrary, mutant miR122 binding sequence had no effect (Fig. 6D). To further corroborate our conclusions, we showed that overexpression of miR-122 completely restored the $\mathrm{FeSO}_{4}{ }^{-}$ induced CCL2 expression back to the normal level (Fig. 6E). Taken together, our data clearly demonstrated that, in the hepatic cells, CCL2 expression is regulated by the most abundant microRNA in the liver, miR-122.

\section{Discussion}

It is generally recognized that iron overload is connected with hepatic inflammation through ROS [21-23]. In the present study, we show that elimination of oxidative stress by the antioxidant Vit.E cannot remove IO-induced hepatic inflammation. In addition, we demonstrated that the miR-122/CCL2 pathway is influenced by iron overload both in vitro and in vivo and the effects of IO are independent of the route of administration and vehicle. Alterations of the miR-122/CCL2 pathway may account for the inability of Vit.E to alleviate IO-induced hepatic inflammation because Vit.E intervention had no effect on the miR-122/ CCL2 pathway. It has been reported that the intracellular iron content may affect the CCL2 expression in neuroblastoma and astrocytoma cell lines [24], rat aorta [25] and heart tissues [26], and mice cardiovascular systems [27]. Otogawa et al. used an acute liver injury model that is induced by thioacetamide [28]. In this case, reduced dietary iron is beneficial in improving the acute liver injuries probably by reducing CCL2 expression. Most importantly, it is observed that in patients with hereditary haemochromatosis, a differential expression of serum CCL2 protein is associated with iron overload [29]. Thus, our observation that IO results in significantly increased CCL2 expression, both in human liver cells lines in vitro and in mice livers in vivo, is consistent with these previous reports.

Furthermore, we investigated the molecular mechanisms underlying the IO-induced CCL2 expression and observed that the reduced expression of miR-122 is associated with IO-induced CCL2 expression. In 2012, two independent groups generated new mice models with liver conditional knockouts of miR-122 [11, 12]. The CCL2 expression in the liver was enhanced in one model but not in the other. Later, another group briefly reported that the decrease of miR-122 may cause an upregulation of CCL2 [30]. In the present study, our data demonstrates that the downregulation of miR-122 mediated the upregulation of CCL2 by directly binding to the 3' UTR of CCL2 mRNA. It is suggested that miRNA biogenesis is partially dependent on the availability of iron-containing haeme [31]. The association with haeme promotes the dimerization of DGCR8. In reconstituted pri-miRNA processing assays, haeme enhances DGCR8 dimerization, a nuclear protein that is involved in the release of the 70-nucleotide precursor-miRNA (pre-miRNA) from the pri-miRNA [32]. However, both studies were conducted in a cell-free system. Further studies will be necessary to investigate how this mechanism influences IO-induced miR-122 deficiency in vivo. Nevertheless, in addition to its direct role in systemic iron homeostasis [13], several key observations also underscore the importance of miR-122 in liver biology and disease, such as lipid metabolism [33, 34], cell differentiation [35], hepatic circadian regulation [36], HCV replication [37], and hepatocellular carcinoma [38]. Most of these processes involve alterations in iron homeostasis.

Based on our data, we propose here a model to elucidate the roles of miR-122/CCL2 under IO (Fig. 7). Serum irons are monitored by a set of cellular proteins, such as TfR1, 
Fig. 7. Systemic iron homeostasis and iron-induced hepatic inflammation are controlled by miR-122.

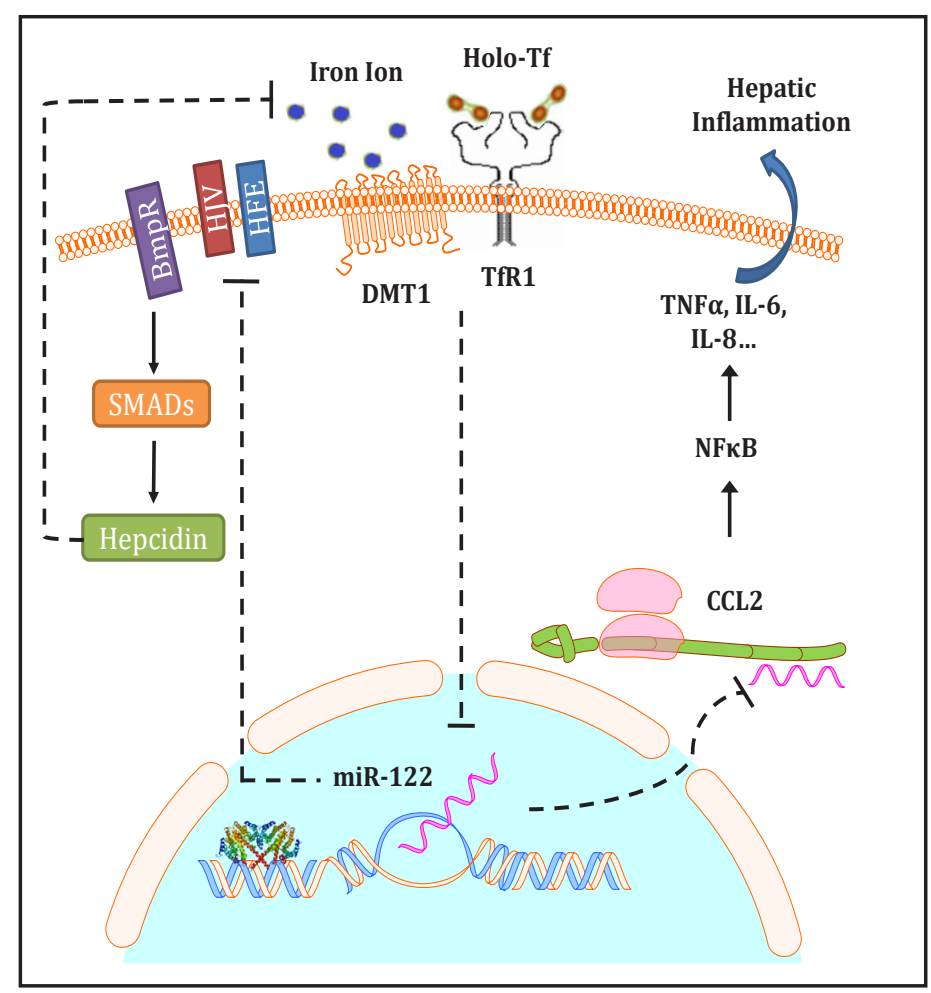

DMT1, BmpR, HJV and HEF[39]. Accumulation of iron in the liver resulted in elevated hepcidin expression through the BMP-SMAD pathway. Increased systemic hepcidin levels inhibit iron release from macrophages and duodenal enterocytes [40]. In addition, IO results in a significantly reduced expression of miR-122, which increases not only HFE and HJV expression [13] but also CCL2 expression, eventually triggering the NFKB-mediated inflammatory response, such as TNF $\alpha$, IL- 6 and IL- $1 \beta$ expression. In summary, our model and studies should be informative for elucidating the mechanism of IO-induced hepatic inflammation and for developing clinical strategies to prevent diseases in the patients with iron overload.

\section{Acknowledgements}

This research was supported in part by grants from the National Natural Science Foundation of China, \#31671236 and Grant E03008 from E-institutes of Shanghai Municipal Education Commission.

\section{Disclosure Statement}

The authors declare no competing interests and no other conflicts of interest about this work.

\section{References}

Starley BQ Calcagno CJ, Harrison SA: Nonalcoholic fatty liver disease and hepatocellular carcinoma: a
weighty connection. Hepatology 2010;51:1820-1832. 


\section{Cellular Physiology Cell Physiol Biochem 2017;44:870-883 \begin{tabular}{l|l} 
and Biochemistry Publisher.1159/000485355 & $\begin{array}{l}\text { (c) } 2017 \text { The Author(s). Published by S. Karger AG, Basel } \\
\text { www.karger.com/cpb }\end{array}$
\end{tabular}

2 Maras JS, Maiwall R, Harsha HC, Das S, Hussain MS, Kumar C, Bihari C, Rastogi A, Kumar M, Trehanpati N, Sharma S, Pandey A, Sarin SK: Dysregulated iron homeostasis is strongly associated with multiorgan failure and early mortality in acute-on-chronic liver failure. Hepatology 2015;61:1306-1320.

-3 Das SK, DesAulniers J, Dyck JR, Kassiri Z, Oudit GY: Resveratrol mediates therapeutic hepatic effects in acquired and genetic murine models of iron-overload. Liver Int 2016;36:246-257.

4 Tacke F: Targeting hepatic macrophages to treat liver diseases. J Hepatol 2017;66:1300-1312.

5 Marra F, Tacke F: Roles for chemokines in liver disease. Gastroenterology 2014;147:577-594 .

6 Dominguez M, Miquel R, Colmenero J, Moreno M, Garcia-Pagan JC, Bosch J, Arroyo V, Gines P, Caballeria J, Bataller R: Hepatic expression of CXC chemokines predicts portal hypertension and survival in patients with alcoholic hepatitis. Gastroenterology 2009;136:1639-1650.

7 Kanda H, Tateya S, Tamori Y, Kotani K, Hiasa K, Kitazawa R, Kitazawa S, Miyachi H, Maeda S, Egashira K, Kasuga M: MCP-1 contributes to macrophage infiltration into adipose tissue, insulin resistance, and hepatic steatosis in obesity. J Clin Invest 2006;116:1494-1505.

-8 Ehling J, Bartneck M, Wei X, Gremse F, Fech V, Mockel D, Baeck C, Hittatiya K, Eulberg D, Luedde T, Kiessling F, Trautwein C, Lammers T, Tacke F: CCL2-dependent infiltrating macrophages promote angiogenesis in progressive liver fibrosis. Gut 2014;63:1960-1971.

-9 Xue J, Chen F, Wang J, Wu S, Zheng M, Zhu H, Liu Y, He J, Chen Z: Emodin protects against concanavalin A-induced hepatitis in mice through inhibiting activation of the p38 MAPK-NF-kappaB signaling pathway. Cell Physiol Biochem 2015;35:1557-1570.

10 Li X, Yao W, Yuan Y, Chen P, Li B, Li J, Chu R, Song H, Xie D, Jiang X, Wang H: Targeting of tumour-infiltrating macrophages via CCL2/CCR2 signalling as a therapeutic strategy against hepatocellular carcinoma. Gut 2017;66:157-167.

11 Hsu SH, Wang B, Kota J, Yu J, Costinean S, Kutay H, Yu L, Bai S, La Perle K, Chivukula RR, Mao H, Wei M, Clark KR, Mendell JR, Caligiuri MA, Jacob ST, Mendell JT, Ghoshal K: Essential metabolic, anti-inflammatory, and anti-tumorigenic functions of miR-122 in liver. J Clin Invest 2012;122:2871-2883.

12 Tsai WC, Hsu SD, Hsu CS, Lai TC, Chen SJ, Shen R, Huang Y, Chen HC, Lee CH, Tsai TF, Hsu MT, Wu JC, Huang HD, Shiao MS, Hsiao M, Tsou AP: MicroRNA-122 plays a critical role in liver homeostasis and hepatocarcinogenesis. J Clin Invest 2012;122:2884-2897.

13 Castoldi M, Vujic Spasic M, Altamura S, Elmen J, Lindow M, Kiss J, Stolte J, Sparla R, D’Alessandro LA, Klingmuller U, Fleming RE, Longerich T, Grone HJ, Benes V, Kauppinen S, Hentze MW, Muckenthaler MU: The liver-specific microRNA miR-122 controls systemic iron homeostasis in mice. J Clin Invest 2011;121:1386-1396.

14 Zhao L, Li W, Zhou Y, Zhang Y, Huang S, Xu X, Li Z, Guo Q: The overexpression and nuclear translocation of Trx-1 during hypoxia confers on HepG2 cells resistance to DDP, and GL-V9 reverses the resistance by suppressing the Trx-1/Ref-1 axis. Free Radic Biol Med 2015;82:29-41.

15 Li S, Ling C, Zhong L, Li M, Su Q, He R, Tang Q, Greiner DL, Shultz LD, Brehm MA, Flotte TR, Mueller C, Srivastava A, Gao G: Efficient and Targeted Transduction of Nonhuman Primate Liver With Systemically Delivered Optimized AAV3B Vectors. Mol Ther 2015;23:1867-1876.

16 Zhao L, Miao HC, Li WJ, Sun Y, Huang SL, Li ZY, Guo QL: LW-213 induces G2/M cell cycle arrest through AKT/GSK3beta/beta-catenin signaling pathway in human breast cancer cells. Mol Carcinog 2016;55:778792.

17 Dai Y, Bae K, Pampo C, Siemann DW: Impact of the small molecule Met inhibitor BMS-777607 on the metastatic process in a rodent tumor model with constitutive c-Met activation. Clin Exp Metastasis 2012;29:253-261.

18 Dai Y, Siemann DW: Constitutively active c-Met kinase in PC-3 cells is autocrine-independent and can be blocked by the Met kinase inhibitor BMS-777607. BMC Cancer 2012;12:198.

19 Bai F, Ho Lim C, Jia J, Santostefano K, Simmons C, Kasahara H, Wu W, Terada N, Jin S: Directed Differentiation of Embryonic Stem Cells Into Cardiomyocytes by Bacterial Injection of Defined Transcription Factors. Sci Rep 2015;5:15014.

20 Vu'o'ng Le B, Khorsi-Cauet H, Villegier AS, Bach V, Gay-Queheillard J: New rat models of iron sucroseinduced iron overload. Exp Biol Med (Maywood) 2011;236:790-799.

21 Seldon MP, Silva G, Pejanovic N, Larsen R, Gregoire IP, Filipe J, Anrather J, Soares MP: Heme oxygenase-1 inhibits the expression of adhesion molecules associated with endothelial cell activation via inhibition of NF-kappaB RelA phosphorylation at serine 276. J Immunol 2007;179:7840-7851. 


\section{Cellular Physiology Cell Physiol Biochem 2017;44:870-883 \begin{tabular}{l|l} 
and Biochemistry Publis.1159/000485355 & $\begin{array}{l}\text { (c) } 2017 \text { The Author(s). Published by S. Karger AG, Basel } \\
\text { www.karger.com/cpb }\end{array}$
\end{tabular}

22 Pham CG, Bubici C, Zazzeroni F, Papa S, Jones J, Alvarez K, Jayawardena S, De Smaele E, Cong R, Beaumont C, Torti FM, Torti SV, Franzoso G: Ferritin heavy chain upregulation by NF-kappaB inhibits TNFalpha-induced apoptosis by suppressing reactive oxygen species. Cell 2004;119:529-542.

-23 Fader KA, Nault R, Kirby MP, Markous G, Matthews J, Zacharewski TR: Convergence of hepcidin deficiency, systemic iron overloading, heme accumulation, and REV-ERBalpha/beta activation in aryl hydrocarbon receptor-elicited hepatotoxicity. Toxicol Appl Pharmacol 2017;321:1-17.

-24 Mitchell RM, Lee SY, Randazzo WT, Simmons Z, Connor JR: Influence of HFE variants and cellular iron on monocyte chemoattractant protein-1. J Neuroinflammation 2009;6:6.

25 Ishizaka N, Saito K, Mori I, Matsuzaki G, Ohno M, Nagai R: Iron chelation suppresses ferritin upregulation and attenuates vascular dysfunction in the aorta of angiotensin II-infused rats. Arterioscler Thromb Vasc Biol 2005;25:2282-2288.

-26 Saito K, Ishizaka N, Aizawa T, Sata M, Iso-o N, Noiri E, Mori I, Ohno M, Nagai R: Iron chelation and a free radical scavenger suppress angiotensin II-induced upregulation of TGF-beta1 in the heart. Am J Physiol Heart Circ Physiol 2005;288:H1836-1843.

-27 Lin H, Li HF, Lian WS, Chen HH, Lan YF, Lai PF, Cheng CF: Thromboxane A2 mediates iron-overload cardiomyopathy in mice through calcineurin-nuclear factor of activated T cells signaling pathway. Circ J 2013;77:2586-2595.

28 Otogawa K, Ogawa T, Shiga R, Nakatani K, Ikeda K, Nakajima Y, Kawada N: Attenuation of acute and chronic liver injury in rats by iron-deficient diet. Am J Physiol Regul Integr Comp Physiol 2008;294:R311-320.

-29 Lawless MW, White M, Mankan AK, O’Dwyer MJ, Norris S: Elevated MCP-1 serum levels are associated with the H63D mutation and not the C282Y mutation in hereditary hemochromatosis. Tissue Antigens 2007;70:294-300.

-30 Li C, Deng M, Hu J, Li X, Chen L, Ju Y, Hao J, Meng S: Chronic inflammation contributes to the development of hepatocellular carcinoma by decreasing miR-122 levels. Oncotarget 2016;7:17021-17034.

-31 Faller M, Matsunaga M, Yin S, Loo JA, Guo F: Heme is involved in microRNA processing. Nat Struct Mol Biol 2007;14:23-29.

32 Barr I, Smith AT, Chen Y, Senturia R, Burstyn JN, Guo F: Ferric, not ferrous, heme activates RNA-binding protein DGCR8 for primary microRNA processing. Proc Natl Acad Sci U S A 2012;109:1919-1924.

-33 Krutzfeldt J, Rajewsky N, Braich R, Rajeev KG, Tuschl T, Manoharan M, Stoffel M: Silencing of microRNAs in vivo with 'antagomirs'. Nature 2005;438:685-689.

34 Esau C, Davis S, Murray SF, Yu XX, Pandey SK, Pear M, Watts L, Booten SL, Graham M, McKay R, Subramaniam A, Propp S, Lollo BA, Freier S, Bennett CF, Bhanot S, Monia BP: miR-122 regulation of lipid metabolism revealed by in vivo antisense targeting. Cell Metab 2006;3:87-98.

35 Kim N, Kim H, Jung I, Kim Y, Kim D, Han YM: Expression profiles of miRNAs in human embryonic stem cells during hepatocyte differentiation. Hepatol Res 2011;41:170-183.

-36 Gatfield D, Le Martelot G, Vejnar CE, Gerlach D, Schaad O, Fleury-Olela F, Ruskeepaa AL, Oresic M, Esau CC, Zdobnov EM, Schibler U: Integration of microRNA miR-122 in hepatic circadian gene expression. Genes Dev 2009;23:1313-1326.

37 Jopling CL, Yi M, Lancaster AM, Lemon SM, Sarnow P: Modulation of hepatitis C virus RNA abundance by a liver-specific MicroRNA. Science 2005;309:1577-1581.

38 Girard M, Jacquemin E, Munnich A, Lyonnet S, Henrion-Caude A: miR-122, a paradigm for the role of microRNAs in the liver. J Hepatol 2008;48:648-656.

39 Hentze MW, Muckenthaler MU, Galy B, Camaschella C: Two to tango: regulation of Mammalian iron metabolism. Cell 2010;142:24-38.

40 Ganz T: Hepcidin and iron regulation, 10 years later. Blood 2011;117:4425-4433. 